\title{
Nutrition status and associated factors among children in public primary schools in Dagoretti, Nairobi, Kenya
}

\author{
*Mwaniki EW, Makokha AN
}

Jomo Kenyatta University of Agriculture and Technology, Kenya

\begin{abstract}
Background: Malnutrition among school-age children is due to inadequacies in one or more of the three main preconditions for good nutrition: food, care and health. Children stunted at school age are likely to have been exposed to poor nutrition since early childhood. Interventions for school age children can supplement efforts to reduce levels of stunting in the preschool years.

Objective: To assess the nutrition status and associated risk factors of children in selected public primary schools in Dagoretti Division, Nairobi.

Methods: Descriptive cross sectional design was used. 208 students aged 4-11years of both gender were randomly selected from four public primary schools in Dagoretti Division. Data was collected from school registers and directly questioning the students, parents /guardians.

Results: Among the children surveyed, $24.5 \%$ were stunted, $14.9 \%$ underweight and $9.7 \%$ were wasted. There were more boys than girls who were stunted. Breakfast contributed $10.2 \%$ of the daily energy intake. Few children consumed foods from more than four food groups. Incidence of diarrhea, colds/coughs increased the risk of stunting and underweight.

Conclusion: Consumption of food which is inadequate in required calories and from less than four varieties of food groups by the children were important predictors of malnutrition.

African Health Sciences 2013; 13(1): 39 - 46
\end{abstract}

\section{Introduction}

Stunting and wasting are wide spread among schoolage children in developing countries ${ }^{1-4}$. High levels of stunting among children suggest that there will also be a long term deficit in mental and physical development that leaves children unable to take maximum advantage of learning opportunities in schools. Epidemiological evidences suggest a strong link between maternal and early childhood under nutrition and increased adult risk of various chronic diseases $^{5}$. Malnutrition is usually the result of a combination of inadequate dietary intake and infection. In children, malnutrition is synonymous with growth failure. Malnourished children are shorter and lighter in weight than they should be for their age ${ }^{6}$.

With the high incidence of poverty and HIV/ AIDS, prevalence of malnutrition is also high ${ }^{7}$. Malnutrition needs to be viewed as an indication of

\begin{tabular}{|l|}
\hline *Corresponding author: \\
Elizabeth W Mwaniki \\
Jomo Kenyatta University of Agriculture and \\
Technology \\
P.O Box 184-00200 \\
Nairobi, Kenya \\
Tel: 0722237600 \\
E-mail. lizmwaniki@yahoo.co.uk \\
\hline
\end{tabular}

African Health Sciences Vol 13 Issue 1 March 2013 inadequate provision of some of the most basic of all human rights. It is also a reflection of inadequate investment and progress in a range of issues related to human capital development and has a significant influence on the future economic development of a country ${ }^{8}$.

A study carried out in Zambia among school children showed that $28.9 \%$ were stunted, $14.5 \%$ underweight and $3.9 \%$ were wasted ${ }^{2}$. Another study on nutritional status (stunting, underweight and wasting) carried out in Nyambene District, Kenya among pupils aged between 5-10 years also reported that girls were better than boys, although the difference was not statistically significant ${ }^{9}$. Another study in Pemba Island Zanzibar showed that the prevalence of stunting increased with age for both school girls and boys ${ }^{10}$.

In Brazil school age boys were significantly more stunted than girls of the same age ${ }^{11}$. In a second study stunting was also found to increase with age where younger school children were reported to have a prevalence of just $2 \%$ compared to $16 \%$ among older school children in Bangladesh ${ }^{12}$. Another study in Brazil found that $21 \%$ of school-age children were stunted and 13\% were underweight. Both indices 
of nutritional status worsened as the study population got older, particularly for boys ${ }^{13}$.

The main aim of this study was therefore to examine the nutritional status and identify the determinants of malnutrition among children in public primary schools in Dagoretti Division Nairobi Kenya.

\section{Methods}

\section{Study setting}

The study was conducted in Dagoretti Division which is within Nairobi Province. Dagoretti Division lies in the extreme Western Division approximately 20 $\mathrm{km}$ from Nairobi City. It consists of several unplanned settlement namely Dagoretti Corner, Congo, Wanyee, Githembe, Ngando, Lenana, Waithaka and Gachui Village. It is estimated that 30\% of the total population comprises of long-term residents, while $70 \%$ have moved into the community from other areas (27). The area's demographics are characterized, amongst others, by a very rapid population growth above the norm for Kenya, which has exerted increasing pressure upon the basic resources of land, housing, water and electricity supply. This, in turn, has contributed to undernutrition, poor sanitation and low levels of environmental health.

\section{Social-demographic information}

A structured questionnaire was used to collect demographic data which included, age, sex and educational level of the children's parents. Data on morbidity occurrence, personal hygiene and food consumption was also collected.

\section{Study Subjects}

This cross sectional study was conducted between November 2009 and February 2010 in 208 children aged between $4-11$ years in four public schools. Four settlements were randomly selected from the existing eight. From each settlement a school was randomly selected. These schools are registered public schools run by the government. Information from the schools' registers was used to stratify the children by sex and age and random number tables used to select the sample. Children who attended these primary schools in the selected area and were 4-11 years old were included in the study sample. Whereas children for whom consent was not given, those who were absent from school during the study period and those who suffered from chronic illness were excluded from the study sample.

\section{Anthropometry}

The foods consumed were classified into relevant food groups that were used to calculate food diversity. These food groups were cereals, legumes, vegetables, meat, dairy, fruits, root and tuber crops and plantains. A minimum of four food groups was considered as adequate diversity. The 24 hour recall was used to obtain the foods consumed for breakfast, lunch and supper. Amounts of foods/ meals served were approximated using standard cups, plates and measuring jug. The children were visited in their homes so that the researcher could administer the questionnaire to their mothers/ caretakers to obtain and record the 24-hour dietary recall information. All the ingredients in the meals and their weights were recorded. The ingredients of the packed school lunch were also recorded. Participants were asked to estimate the child's intake of a specified food using standard cups and plates and measuring jug. The utensil used to serve the child was displayed and the extent to which it fills was explained before the approximations were made. The combined caloric contributions of breakfast and supper (two meals consumed at home) were also computed using the Nutri-Survey programme. The adequacy of caloric intake was expressed as the proportion of the total daily caloric intake. Food tables were used to estimate the adequacy of the energy food consumption. Frequency of washing hands with water and soap at critical times was assessed. Children below six years of age were excluded to improve reliability of the self-reported hygiene practices. Anthropometric data, which included, height, weight and age was collected from the primary school children. Date of birth was obtained from the schools' records. EPI INFO (Version 3.3.2) was used to calculate Height-for-age (HAZ), Weight- for- age (WAZ) and Weight- forHeight (WHZ) Z-scores. Children with HAZ, WAZ and WHZ scores between -2.99 and -2.00 were considered to have moderate stunting, underweight and wasting respectively, while those with -3.00 and below were severely stunted, underweight and wasted respectively ${ }^{14}$. These variables were considered as the dependent variables during statistical analysis.

\section{Statistical analysis}

Data were analysed using Statistical Package for Social Sciences, SPSS (Version 14.0). Nutri Survey programme was used to calculate the caloric contribution of each meal to the children's daily 
caloric intake. Statistical analysis included t-test for proportions which was used to test the differences in proportions of children with adequate and inadequate diversity of diet, prevalence of malnutrition by sex and the prevalence of morbidity by sex and age. This test was suitable because the sample was randomly selected and the variables were categorical. Pearson product moment was used to test the relationship between the risk factors and malnutrition indices. This relationship was assumed to be linear. Statistical significance was set at $\mathrm{p}<$ 0.05 .

\section{Ethical consideration}

The objectives of the study were communicated to the school children and participation was completely voluntary. Study participants provided written consent prior to participation. Informed consent forms were signed by the parents or guardians of the children before commencing the study and there was a $100 \%$ participation rate. The information obtained from the participants was not divulged and was held in confidence. Permission was sought from all the relevant authorities: Ministry of Education Science and Technology and from Kenya Medical Research Institute Ethical and Review Board.

\section{Results}

The sample consisted of children who were equally distributed between age 4 and 11 years. These age categories of children still need care and supervision, particularly in matters of personal hygiene. The children were also distributed equally among boys and girls as shown in table 1 .

Table 1: Distribution of children by age, sex and school

\begin{tabular}{llll}
\hline & & n (208) & \% \\
\hline \multirow{4}{*}{ Age in years } & Rafiki & 51 & 24.6 \\
& Waithaka & 54 & 25.8 \\
\multirow{4}{*}{ Sex } & Grace & 52 & 25 \\
& $8-11$ & 104 & 50 \\
& Boys & 104 & 50 \\
& Girls & 104 & 50 \\
\end{tabular}

\section{Food intake}

The children took the three main meals of the day that is breakfast, lunch and supper throughout the week. To determine the contribution made by each food consumed by the children, children's total food intake by weight was calculated. The foods were classified into 12 different food groups. The food groups found in the children's diet and their contribution by weight to the total diet intake are as shown in table 2. Tea/cocoa contributed the highest amount by weight $(480.6 \mathrm{~g})$ and its proportion of the total dietary intake by weight was $21.1 \%$.

Table 2: 24 hour recall of the foods consumed by the children

\begin{tabular}{|c|c|}
\hline $\begin{array}{l}\text { Amou } \\
\text { from ea } \\
(\mathrm{g})(\mathrm{Pe} \\
\text { contrib } \\
\text { total d }\end{array}$ & $\begin{array}{l}\text { int consumed } \\
\text { ach food group } \\
\text { rcentage } \\
\text { oution to the } \\
\text { iet) }\end{array}$ \\
\hline Cereal based grains & $357.7(18.4 \%)$ \\
\hline (Ugali, maize and beans, & \\
\hline Rice, Chapattis, bread, porridge) & \\
\hline Vegetables (cabbage, Kales, spinach & $248.2(12.8 \%)$ \\
\hline $\begin{array}{l}\text { Legume grains ( Beans, Green } \\
\text { grams, Lentils) }\end{array}$ & $292.8(15.1 \%)$ \\
\hline Dairy (Fresh or fermented milk) & $188.2(9.7 \%)$ \\
\hline Eggs & $18.2(0.9 \%)$ \\
\hline Meat (chicken, fish, beef) & $166(8.5 \%)$ \\
\hline Fruits & $60.7(3.1 \%)$ \\
\hline Spread (margarine, butter, fruit jam & $3.8(0.2 \%)$ \\
\hline Sugar & $47.9(2.5 \%)$ \\
\hline Tea/Cocoa & $408.6(21.1 \%)$ \\
\hline Plantain & $92.1(4.7 \%)$ \\
\hline $\begin{array}{l}\text { Tubers and Roots (Irish/Sweet } \\
\text { potatoes, Carrots) }\end{array}$ & $56.4(2.9 \%)$ \\
\hline Total & $1940.6(100 \%)$ \\
\hline
\end{tabular}

A total of 63 food items were consumed by the children. A significantly $(\mathrm{p}=0.000)$ small proportion $45.2 \%$ of the children consumed four or more food groups compared with $54.8 \%$ children who consumed less than four food groups. The total mean energy intake among the children was $1890 \mathrm{Kcl}$ per day. Breakfast contributed the lowest mean energy intake for the day $(10.2 \%)$ (table 3).

Table 3: Adequacy of energy intake among the children

\begin{tabular}{lcc}
\hline Meal & $\begin{array}{l}\text { Mean (energy intake Kcal) } \\
\text { Children } \\
(\mathbf{n}=\mathbf{2 0 8})\end{array}$ & $\begin{array}{l}\text { Percent } \mathbf{( \% )} \\
\text { contribution }\end{array}$ \\
\hline Breakfast & $193( \pm 15.3)$ & 10.2 \\
Lunch & $841( \pm 59.6)$ & 44.5 \\
Supper & $856( \pm 111.2)$ & 45.3 \\
Total & $1890( \pm 64.3)$ & 100 \\
\hline
\end{tabular}


The total energy intake was computed and compared to the recommended daily allowance for each age set and by sex of children (15) these were 1352 and $1698 \mathrm{Kcl}$ for 4-6 and 7-9 year age groups, whereas for the 10-11 year group, they were $2326 \mathrm{Kcl}$ for girls and $2824 \mathrm{Kcl}$ for boys. Only $17.3 \%$ of the children failed to meet the recommended daily allowance energy intake (table 4).

Table 4: Proportion of children who took adequate calories

\begin{tabular}{lll}
\hline Age (years) & Sex & Proportion of children \\
\hline $4-6$ & Boy & $33(15.9 \%)$ \\
& Girl & $31(14.9 \%)$ \\
$7-9$ & Boy & $35(16.8 \%)$ \\
& Girl & $28(13.5 \%)$ \\
$10-11$ & Boy & $24(11.5 \%)$ \\
& Girl & $21(10.1 \%)$ \\
Total & & $172(82.7 \%)$ \\
\hline
\end{tabular}

\section{Malnutrition}

The boys had a higher rate of stunting and underweight compared to girls. However girls had a higher rate of wasting than boys. These differences were not significant (table 5).

\section{Associated factors}

The children in the four schools suffered from various infections whose symptoms included colds/ flu, diarrhea, vomiting, fever and skin rashes. Morbidity rates were significantly $(\mathrm{p}<0.05)$ higher among boys compared with girls among both 4-7 and 8-11 years old children. Vaccination rates were higher among boys compared with girls ages 4-7 $(37 \%, 11.5 \%)$ and $8-11(35.9 \%, 15.6 \%)$ years respectively. A high proportion (76.3\%) of children reported washing hands with soap after visiting the toilet the day preceding the interview. The factors that showed significant difference were correlated to the malnutrition indices of stunting, underweight and wasting (table 5). The proportion of stunted and underweight children was inversely and significantly $(p<0.05)$ correlated with children's energy intake, variety of foods, vaccination rate for both girls and boys and washing hands with soap. Diarrhoea and colds/cough were positively and significantly correlated to the proportion of stunted and underweight children. Wasting was inversely and significantly correlated with energy intake for boys 8-11years.

To identify the determinants of malnutrition, multivariate analysis was performed. Table 6 shows that boys aged 4-7 and 8-11years a higher risk of being stunted as compared to girls of the same age. Similarly children who had suffered from diarrhea and colds and flu had a higher risk of being stunted than those who were healthy. Risk of stunting was 3.3 times lower among children who had adequate energy intake compared to the children who took inadequate energy.

\section{Table 5: Prevalence of malnutrition in children by sex}

\begin{tabular}{|c|c|c|c|c|c|}
\hline \multirow{2}{*}{$\begin{array}{l}\text { Nutritional status by sex } \\
(\mathrm{Z} \text { score } \leq 2.00)\end{array}$} & \multirow[t]{2}{*}{ Sex } & \multicolumn{4}{|c|}{ Proportion of malnourished children } \\
\hline & & $\mathrm{n}$ & $\%$ & Total n (\%) & $\mathrm{p}$ \\
\hline \multirow[t]{2}{*}{ Stunting } & Boys $(n=104)$ & 28 & 13.5 & $51(24.5 \%)$ & 0.421 \\
\hline & Girls $(n=104)$ & 23 & 11.1 & & \\
\hline \multirow[t]{2}{*}{ Underweight } & Boys $(n=104)$ & 16 & 7.7 & $31(14.9 \%)$ & 0.846 \\
\hline & Girls $(n=104)$ & 15 & 7.2 & & \\
\hline \multirow[t]{2}{*}{ Wasting } & Boys $(n=104)$ & 8 & 3.8 & $20(9.7 \%)$ & 0.509 \\
\hline & Girls $(n=104)$ & 12 & 5.8 & & \\
\hline
\end{tabular}

Children who took adequate energy had a lower risk of being underweight than those who took inadequate energy. Children who had four or more varieties of food had a lower risk of under weight than those who took less than four varieties of food. Children who had diarrhea, coughs/colds had respectively 3.1 and 2.2 times higher risk of being underweight compared to the healthy children. Washing hands with soap lowered the risk of underweight by 1.9 times.

Boys aged 8-7 years who took adequate energy had 2.0 times lower risk of being wasted 
Table 6: Correlation coefficient between associated factors and malnutrition among children

\begin{tabular}{|c|c|c|c|c|}
\hline \multirow[t]{2}{*}{ Variable } & \multicolumn{2}{|c|}{ Malnutrition } & \multirow[b]{2}{*}{$\begin{array}{c}\text { Wasting } \\
\mathrm{r}\end{array}$} & \\
\hline & $\begin{array}{c}\text { Stunting } \\
\mathrm{r}\end{array}$ & $\begin{array}{c}\text { Underweight } \\
\mathrm{r}\end{array}$ & & \\
\hline Age of child in years & $\begin{array}{ll}\mathrm{s} & 0.33^{*}\end{array}$ & 0.01 & 0.07 & \\
\hline \multicolumn{4}{|l|}{ Energy intake } & \\
\hline $4-7$ years & $-0.79 * * *$ & $-0.23 *$ & 0.08 & \\
\hline $8-11$ years & $-0.31 *$ & $-0.47 * *$ & $-0.45^{* *}$ & \\
\hline Boys & $-0.28^{*}$ & $-0.29 *$ & -0.09 & \\
\hline \multicolumn{4}{|l|}{ Girls } & \\
\hline \multicolumn{4}{|l|}{ Vaccination } & \\
\hline Girls & $-0.36^{*}$ & -0.01 & -0.01 & \\
\hline Boys & $-0.76 * * *$ & -0.03 & -0.08 & \\
\hline \multicolumn{4}{|l|}{ Morbidity } & \\
\hline Diarrhea & $0.82 * * *$ & $0.90 * * *$ & 0.03 & \\
\hline Cough/colds & $0.36^{*}$ & $0.29 *$ & 0.03 & \\
\hline \multicolumn{4}{|c|}{ Hygiene practice } & \\
\hline $\begin{array}{l}\text { Washing hands (with } \\
\text { soap) }\end{array}$ & $-0.91 * * *$ & $-0.39 *$ & -0.09 & \\
\hline
\end{tabular}

\section{Discussion}

The impact of malnutrition is multifarious. It has an all pervasive impact on the physical well-being and socio-economic condition of a nation. Both bivariate and multivariate analysis indicated inadequate energy intake was an important risk factor for all the three indices of malnutrition (stunting, wasting and underweight). Other variables for example socio-economic status and educational level of parents could represent a source of bias. However this study demonstrates that malnourished children had significantly higher incidence of morbidity, inadequate calorie intake, low frequency of washing hands at critical times and inadequate variety of foods.

The findings of this study showed that the contribution of the cereal food group fell far below the recommendation of food based dietary guidelines of $55 \%$ (16: 17). However the findings are similar to those of the 1999 micronutrient survey, which reported a relatively low consumption of fruits in Kenya ${ }^{18}$. Similarity the low cereal consumption and its highest contribution to the proportion of the total mean weight of foods consumed was not unexpected, since the community's agricultural activities had declined due to urbanization. Therefore, to a large extent, the community depended on purchased food rather than on own-produced food. The calories (less than $12 \%$ of the daily energy intake) derived from breakfast, equivalent to four slices of bread was too low to enable the children to perform adequately until lunch. This suggests that the children were hungry for a great part of the morning. Supper was a more important source of energy $(45.3 \%)$ compared to lunch (44.5\%). The low energy intake observed in this group is of concern. These findings are similar to the Pakistan study which observed that school children had lower intakes of calories for breakfast (less than 10\%).

Conversely in the same study lunch contributed a higher proportion (46.3\%) of calories compared to supper (44.4\%) for the Pakistan school children ${ }^{7}$. The proportionately high contribution of lunch and supper to daily energy intake implies that more emphasis was placed on these two meals than on breakfast. The mean energy intake for individual children didn't meet the energy requirements for all children. However, $82.7 \%$ of the children met their energy requirements. This proportion of children was high compared to the Western Kenya findings 
where only $63.7 \%$ of school children met the recommended daily energy allowance ${ }^{19}$. Foods that provide the body with adequate nutrients to support all the functions are associated with good health ${ }^{20}$. The children whose energy intake fell below the recommended intake was an indication that even though the diet was varied, for some children the diet was still inadequate. It could therefore be suggested that for those children whose energy intake fell below the recommended, they were at risk of suffering from nutritional deficiencies. The children who did not meet the energy requirements possibly were given inadequate amounts of food.

Fewer children were served with four or more food groups (45.2\%). These results are similar to a Pakistan study which found $42.2 \%$ of school children consumed four or more food groups ${ }^{7}$. Children who consumed foods from four or more food groups had a lower risk of being stunted and underweight compared to those who took foods from less than four food groups. The consumption of a varied diet is associated with increased intake of energy and better health ${ }^{21}$. Children may be served with large servings of starchy cereals because they are bulky thus giving satiety value.

This study found that malnutrition levels were high among school going children just as in children below five years. The overall prevalence of stunting stood at $24.5 \%$. The school children in this sample had a lower prevalence of stunting than in the study carried out in Zambia among school children where $28.9 \%$ were stunted ${ }^{2}$. Children with low height for age are stunted. This condition is usually associated with long term chronic malnutrition and long term factors such as frequent infection and poor feeding practices ${ }^{6}$. Children stunted at school age are likely to have been exposed to poor nutrition since early childhood ${ }^{22}$. Boys aged 4-7 and 8-11years had a higher risk of being stunted than girls of the same age. The high levels of stunting among boys could have been contributed by high prevalence of disease among boys which could also be associated to the low rates of hand washing with soap. Inadequate energy intake among the children could have contributed to the high stunting levels among boys than girls mainly because boys (above 10 years of age) require more food than girls of the same age $^{15}$. It could also be explained by the fact that more girls than boys were involved in food preparation and therefore likely to consume more food than boys overtime. Further, since stunting increases with age, it is likely that more boys than girls were stunted in their childhood.

Stunting was found to significantly increase with age. These findings were similar to those of the study in Brazil which found stunting worsened as the study population got older ${ }^{13}$. This could reflect longer exposure to chronic malnutrition.

Underweight rate $(14.9 \%)$ was similar to that of the study carried out in Zambia among school children which found out that $14.5 \%$ were underweight ${ }^{2}$. Adequate energy intake, intake of four or more varieties of foods and washing hands with soap at critical times had a protective effect on the children against underweight. Conversely, inadequate energy intake, taking food from less than four varieties of food groups, failure to wash hands at critical times and incidence of diarrhea, coughs/colds increased the risk of underweight. Deteriorating standards of living, disease prevalence and increase in food prices could have contributed to the high prevalence of under nutrition. A child's Weight-for-Age measure reflects both previous growth and present nutritional conditions. Hence the high rate of underweight reflects the presence of both long term chronic malnutrition and recent food insecurity or illness. Underweight among school children can reflect prenatal under nutrition, infection and possibly inadequate attention by care givers ${ }^{16}$.

This could imply that the children were disadvantaged in terms of care and may have had inadequate intake of energy nutrients in the recent past. The high dependence on cereals and legume grains could have resulted in extremely high phytate and fiber content of these diets thus rendering the energy nutrient bio unavailable ${ }^{23}$. This prevalence of wasting was high $(9.7 \%)$ in this group. The findings are different from the study carried out in Zambia among school children which found that $3.9 \%$ were wasted ${ }^{2}$. Another study in Nicaragua found that $5 \%$ of school children were wasted ${ }^{24}$. Boys aged 8-11 years who took adequate calories had a lower risk of being wasted compared to those of the same age who took inadequate calories.

A child's weight-for-height measure is an indicator of nutritional wasting and primarily reflects severe short term deprivation of food in his/her immediate nutritional history, for example during episodes of disease such as diarrhea or in times of food shortage ${ }^{25}$. Adequate dietary intake is essential for good nutrition. It may, however, not be sufficient, because the presence of disease can result in reduced 
bioavailability, increased needs, nutrient losses or loss of appetite and can thus be an immediate cause of malnutrition ${ }^{26}$. The prevalence of wasting in this sample could have resulted from the high prevalence of diarrhea and cough/colds resulting in reduced appetite for food. Possibly, some children suffered from more than one infectious disease thus culminating in this high rate of nutritional wasting. They could also have suffered acute food crisis thus becoming severely malnourished.

\section{Limitations of the study}

Longitudinal study could have enabled study subjects to be profiled overtime.

Hygiene practices could have been over reported as is common with self-reported hygiene practices. Educational level and socio economic status of the children's parents could represent a source of bias.

\section{Conclusion}

Consumption of food which is inadequate in required calories and from less than four varieties of food groups by the children were important predictors of malnutrition.

\section{References}

1. Druck B. The dance of climate change and hidden hunger. The Sight and Life Magazine (2010).: No 3/2010: 40-59. Waldkirch.

2. Gillespie S, Kadiyata S. Rethinking food aid to fight AIDS. International nutrition foundation for United Nations University. Food and nutrition bulletin 2004; 25(3): 33-41

3. World Health Organization (WHO). Childrenschools and health; their nutrition and health in Kenya. WHO Global database on child growth and malnutrition (2008). Retrieved from www.schoolsandhealth.org on 24/1/2012. Page. $17-20$

4. Burbano C, Bundy D, Grosh M, Gelli A, Jukes $\mathrm{M}$ and Drake L. Rethinking School Feeding: Social Safety Nets, Child Development and the Education Sector. The International Bank for Reconstruction and Development/the World Bank (2009). Washington DC: page 33-36

5. Allen L and Gillespie S. What Works? A Review of the Efficacy and effectiveness of Nutrition Interventions. United Nations Administrative Committee on coordination Sub-Committee on Nutrition (2001). Asian Development Bank. page 8-16
6. United Nations International Children's Education Fund (UNICEF). Nutritional assessment in Kenya, UNICEF (2000), Nairobi, Kenya. Page. $1-12$

7. United Nations International Children's Education Fund (UNICEF). Water, Sanitation, and Hygiene Annual Report (2009). Accessed August 5, 2009. Available at: www.unicef.org/wash. Pp. 519

8. World Health Organization (WHO). Towards the realization of free basic sanitation: Evaluation, Review and Recommendations (2010). WRC Project NOK. Pg1743-1520

9. Meme M, Kogi-Makau W, Muroki M, and Mwadime K. Energy and protein intake and nutritional status of primary school children 5 to 10 years of age in schools with and without feeding programmes in Nyambene district, Kenya. Kenyatta University (1998), Nairobi Kenya. Pp 1-24

10. Stoltzfus R. Linear growth retardation in Zanzibari school children. Journal of Nutrition 2004; 127: 1099-1105.

11. Parraga I. Gender differences in growth of school-age children with schistosomiasis and geohelminth infection. American Journal of Tropical Medicine and Hygiene 2000; 55: 150-156.

12. Ahmed F. Dietary pattern, nutrient intake and growth of school children in urban Bangladesh. Public Health Nutrition 2005; 1: 83-92

13. Parraga I Growth deficits in school age children in Brazil. American Journal of Clinical Nutrition 2006; 50: 687-696

14. World Health Organization (WHO). WHO Child growth standards length/ height for age, weight for age, weight for length or height and body mass index for age methods of development. WHO (2006). Geneva. Page 43

15. Food and Agriculture Organization (FAO). Human energy requirements. Report of a joint FAO/WHO/UN (2004). WHO Geneva. Page $5-10$

16. World Food Programme. Hunger (2010), Accessed online:http://www.wfp.org/hunger/ faqs.page 82

17. Maunder E, Matji J, and Hatshwayo-Molea T. Enjoy a variety of foods-difficult but necessary in developing countries. South African Journal of clinical nutrition 2001; 14: 7S-11S

18. Ministry of Health $(\mathrm{MoH}) /$ United Nations International Children's Education 
Fund (UNICEF). Anemia and status of iron, vitamin $A$ and Zinc in

Kenya. Inc. The 1999 National micronutrient survey report (2001): UNICEF. Pp. 93

19. Nokuthula V. Food consumption in Kenya (2009). University of Pretoria (accessed on 14 August, 2011). Pp. 73-84

20. Krause M and Mahan L. Food nutrition and diet therapy (1984). Saunders Company. London .pp39

21. Gibson R, and Hotz M. Dietary diversification/ modification strategies to enhance micronutrient content and bioavailability of diets in developing countries. British Journal of Nutrition 2001; 85: s159-s166

22. World Food Programme (WFP). School children nutrition. WFP (2004). London UK. pp. 69

23. Van Lieshout $M$ and West $C$ Introduction to malnutrition. In micronutrient malnutrition course for Southern Africa. ARC- Animal nutrition and Animal Production Institute, Pretoria, Centre for nutrition, (2004). University of Pretoria, Pretoria,
Micronutrient initiative education, Hellen Keller International, Dakar, Bangladesh In cooperation and with support from Ghent University, Belgium. Pp. 24-27

24. Morris S, Flores R, Olinto P, Medina J. Monetary incentives in primary health care and effects on use and coverage of preventive health care interventions in rural Honduras: cluster randomized trial, Lancet 2004; 364: 2030-2037.

25. Armstrong H, Lhotska L and Engle P. The care initiative: Assessment analysis and action to improve care of nutrition (1997). New York. UNICEF pp1-12

26. Stratton R, Green C, Elias M. Disease-Related Malnutrition: An Evidence-Based Approach to Treatment. CABI Publishing (2003), Wallingford, pp. 848.

27. Government of Kenya (GOK). Ministry of Planning and National development, Census Report 2009 Kenya population and housing census results. Kenya National Bureau of Statistics, GOK Printers (2010), Nairobi. 5-11 